\title{
DIVERSIDADE GENÉTICA DE Psidium guineense EM DUAS LOCALIDADES NO ESPÍRITO SANTO
}

\author{
Drielli Canal ${ }^{1}$ \\ Carolina de Oliveira Bernardes ${ }^{2}$ \\ Marina Santos Carvalho ${ }^{3}$ \\ Amélia Carlos Tuler ${ }^{4}$ \\ Adésio Ferreira ${ }^{5}$ \\ Marcia Flores da Silva Ferreira ${ }^{6}$
}

\begin{abstract}
Resumo: Psidium guineense Swartz pertence à família Myrtaceae, oferece potencial para exploração comercial e em virtude das propriedades nutricionais e farmacêuticas desperta a atenção da indústria. Entretanto, por ser uma espécie poliplóide, estudos de diversidade genética são escassos, dado a dificuldade das análises. O objetivo deste estudo foi avaliar a diversidade genética de duas populações $P$. guineense em dois municípios do estado do Espírito Santo, utilizando sete marcadores microssatélites. Todos os locos analisados foram polimórficos com média de 11,14 por locus. O método UPGMA agrupou os genótipos em dois grupos principais, diferenciando as populações das duas localidades. Dois índividuos de Águia Branca alocaram-se separadamente dos demais, demonstrando divergência genética. Os marcadores SSR utilizados neste estudo demonstraram eficiência na detecção de polimorfismos moleculares, revelando que houve grande diversidade genética entre os indivíduos das duas populações amostradas, sendo importantes para o melhoramento e conservação da espécie.
\end{abstract}

Palavras-chave: Marcadores Microssatélites; Poliplóide; Myrtaceae; Araça; Conservação.

\footnotetext{
1 Graduanda em Ciências Biológicas Bacharelado/Universidade Federal do Espírito Santo, Brasil. E-mail: drielliufes@gmail.com.

2 Doutoranda em Genética e Melhoramento/Universidade Federal do Espírito Santo, Brasil. E-mail: carolinabernardes84@yahoo.com.br.

3 Doutoranda em Genética e Melhoramento/Universidade Federal do Espírito Santo, Brasil. E-mail: marinasantosufes@gmail.com.

4 Doutoranda em Botânica/Universidade Federal do Espírito Santo, Brasil. E-mail: ameliatuler@gmail.com.

5 Professor Adjunto III de Genética e Melhoramento/Universidade Federal do Espírito Santo, Brasil. E-mail: adesioferreira@gmail.com.

6 Professor Associado do Departamento de Biologia, UFES/Alegre -ES, Brasil. E-mail: marcia.ferreira@ufes.br.
} 